\title{
Contribuição da Casa Rural Familiar para a permanência da família no campo: o caso de Realeza/PR
}

\author{
Ronaldo Aurélio Gimenes Garcia ${ }^{1}$, Eloir Angelo Barbacovi ${ }^{2}$ \\ ${ }^{1}$ Universidade Federal da Fronteira Sul - UFFS. Campus de Realeza. Avenida Edmundo Gaievski 1000. Realeza \\ - PR. Brasil. ronaldo.garcia@uffs.edu.br. ${ }^{2}$ Universidade Federal da Fronteira Sul - UFFS.
}

RESUMO. O presente trabalho refere-se a um estudo de caso com o objetivo central de analisar qual a contribuição dada pela Casa Familiar Rural de Realeza (CFR), junto à agricultura familiar. Visa compreender, a partir da prática pedagógica da alternância, a realidade das famílias do meio rural, no que diz respeito à sua a qualidade de vida no campo, sua sustentabilidade e aos aspectos sociais, ambientais e econômicos. Para o desenvolvimento da pesquisa nos utilizamos de diversos instrumentos para o levantamento de fontes. Entre estes à observação participativa que nos permitiu vivenciar todas as atividades realizadas pela escola. Valemo-nos de entrevista, com questões abertas para que os colaboradores da pesquisa se sentissem livres para se manifestar com suas próprias palavras. Foram entrevistadas sete pessoas, dentre essas a coordenadora da CFR e responsável técnico da instituição, duas professoras, quatro pais de alunos ou ex-alunos e um representante da Emater local. Traçamos um breve histórico da região, analisamos aspectos da implantação das CFRs no Estado. Foram abordados também conceitos teóricos sobre Pedagogia da Alternância, as praticas pedagógicas utilizadas pela escola e seus reflexos no contexto de formação para o desenvolvimento local.

Palavras-chave: Agricultura Familiar, Casa Familiar Rural, Educação do Campo, Sustentabilidade. 


\title{
Rural Family House contribution for keeping families in the countryside: the case of Realeza/PR
}

\begin{abstract}
This paper refers to a case study with the main objective to analyze the contribution given by the Realeza's Rural Family House (CFR), along with family farming. It aims to understand from the teaching of alternation practice, the reality of families in rural areas, with regard to their quality of life in the countryside, its sustainability and the social, environmental and economic aspects. For the development of research we use of various instruments to survey sources. Among these participatory observation that allowed us to experience all the activities of the school. We have used interview with open questions so that search employees feel free to express in their own words. Seven people were interviewed, among these the coordinator of the CFR and technical head of the institution, two teachers, four parents of students or former students and a representative of the local Emater. We trace a brief history of the region, we analyze aspects of the implementation of the CFRs in the Paraná State. We were also discussed theoretical concepts of Pedagogy of Alternation, the pedagogical practices used by the school and their reflections in the context of training for local development.
\end{abstract}

Keywords: Family Farming, Rural Family House, Rural Education, Sustainability. 


\section{Contribución de la Casa Rural Familiar para la permanencia de la familia en el campo: el caso de Realeza/PR}

RESUMEN. El presente trabajo refieres a un estudio de caso con el objetivo principal de analizar cual la contribución dada por la Casa Familiar Rural de Realeza (CFR), junto con la agricultura familiar. Tiene como objetivo entender a partir de la enseñanza de la práctica de alternancia, la realidad de las familias de las zonas rurales, con relación a su calidad de vida en el campo, su sostenibilidad y los aspectos sociales, ambientales y económicos. Para el desarrollo de la investigación fue utilizado varios instrumentos para examinar fuentes. Entre ellas la observación participativa, que nos permitió experimentar todas las actividades realizadas por la escuela. Hemos utilizado la entrevista con preguntas abiertas para que los entrevistados se sentir libres para expresar con sus propias palabras. Fueron entrevistados siete personas, entre ellas, la coordinadora del CFR y responsable técnica de la institución, dos maestras, cuatro padres de los estudiantes, o ex estudiantes y un representante de la Emater local. Trazamos una breve historia de la región, y analizamos aspectos de la implantación de las CFRs en el Estado. También fueron discutidos conceptos teóricos acerca de la Pedagogía de la Alternancia, las prácticas pedagógicas utilizadas por la escuela y sus reflejos en el contexto de la formación para el desarrollo local.

Palabras clave: Agricultura Familiar, Casa de la Familia Rural, La Educación en el Campo, Sostenibilidad. 


\section{Introdução}

O presente trabalho trata de um estudo de caso e tem como propósito analisar qual a contribuição da Casa Familiar Rural de Realeza no Estado do Paraná frente à comunidade do campo do município que vivencia a agricultura familiar. Visa compreender, a partir da prática pedagógica da alternância, a realidade das famílias do meio rural, no que diz respeito ao seu envolvimento no processo de sustentabilidade e aos aspectos sociais, ambientais e econômicos que o envolvem.

Para o desenvolvimento da pesquisa nos velemos de diversos instrumentos para coleta de informações. Uma das estratégias utilizadas para coleta de dados foi à observação participativa com a permissão previamente concedida pela instituição. A observação participativa nos permitiu vivenciar todas as atividades realizadas pela escola.

Ainda nos valemos de entrevista, com questões semiestruturadas gravadas em áudio. Foram entrevistadas sete pessoas, conforme suas disponibilidades, dentre essas a coordenadora da CFR e responsável técnica da Escola, duas professoras, quatro pais de alunos ou exalunos e um representante da Emater ${ }^{\mathrm{i}}$ local. Trabalhamos com questões abertas, para que os colaboradores se sentissem livres para manifestar, sem se limitarem a escolha entre alternativas. Para melhor identificarmos suas falas no texto, os participantes foram nominados da seguinte forma: os professores como Prof1 e Prof2; já os pais de alunos ou ex-alunos como Pai1, Pai2, Pai3, Pai4; quanto à coordenadora da CFR e responsável técnico da mesma esta será nominada como Coordenadora e o representante da Emater com o nome da empresa.

Assim, no decorrer do artigo, na primeira parte traremos um breve histórico da região e sua formação agrícola. Com o objetivo de melhor compreendermos a importância da Casa Familiar Rural de Realeza PR, abordamos sobre o papel da agricultura familiar e a delimitação do espaço ocupado por este setor dentro do amplo contexto da economia brasileira e regional. $\mathrm{Na}$ segunda parte deste texto traremos algumas reflexões a respeito da implantação das CFRs no Estado do Paraná. Também discutimos os conceitos teóricos sobre a pedagogia adotada pelas CFRs. Por fim, tratamos das práticas pedagógicas utilizadas pela escola, seus reflexos no contexto de formação, como são realizados os trabalhos para o desenvolvimento local e os resultados obtidos. 
Formação da agricultura regional e local

A ocupação da região sudoeste paranaense se deu a partir de um programa de implantação de colônias agrícolas nacionais, promovido pelo então Presidente da República Getúlio Vargas em 1945, visando o aproveitamento de terras supostamente devolutas na fronteira com o Paraguai e a Argentina (Martins, 1986). Para isso, Vargas criou a CANGO (Colônia Agrícola Nacional General Osório) que segundo Gomes (2005 p. 16) "nos primeiros anos de atuação, ... dava terra aos agricultores bem como uma ajuda técnica, de assistência social e de infraestrutura", mas, não lhes dava o título de propriedade da terra, porque essa estava em disputa jurídica entre a União e o governo do Paraná. A companhia colonizadora CITLA (Clevelândia Industrial e Territorial Ltda.), formada por particulares, também se instalou na região na condição de herdeira das glebas, resultado de longo processo judicial envolvendo o poder público e particulares (Martins, 1986). O conflito pela posse da terra se deu nos atuais municípios de Capanema, Dois Vizinhos, Francisco Beltrão, Pato Branco, Pranchita, Santo Antônio do Sudoeste e Verê (Gomes, 2005).

Ainda de acordo com Gomes (2005), o estopim para a revolta dos colonos foi à entrada em 1956 de duas outras colonizadoras ligadas à CITLA: a COMERCIAL (Companhia Comercial e Agrícola Paraná Ltda.) e a APUCARANA (Companhia Imobiliária Apucarana Ltda.). Contudo, em 1951, ano em que surgem as primeiras reações ainda pacíficas dos posseiros até 1957, ano em que ocorreu o confronto armado, a questão legal da propriedade das terras do sudoeste não se definiu. A solução definitiva só viria a ocorrer a partir de 1962. Entre 1962 a 1973 realizou a "reforma agrária" no sudoeste, concedendo cerca de 43 mil títulos de propriedade numa área de 545 mil hectares de terras (Gomes, 2005).

$\mathrm{Na}$ prática, a região não foi colonizada e sim ocupada como argumenta Gomes (2005) e Martins (1986). Esta forma de ocupação gerou uma desordem na formação das propriedades do ponto de vista ambiental, com lotes de todos os formatos e tamanhos imagináveis. Isso fez com que os produtores familiares explorarem o máximo os recursos naturais, ocupando áreas bem declivadas ou usando as beiras (margens) de rios. A ocupação foi a principio com pequenas roças de toco, depois veio à suinocultura. Essa configuração na realidade é o que permanece até hoje. O que houve foi a incorporação de propriedades, saindo de uma média de doze hectares ${ }^{\text {ii }}$ (ha) já para 
vinte e cinco ha na década de oitenta, depois vinte e oito na década de noventa e hoje passa de quarenta hectares a média das propriedades.

A distribuição de terras em pequenos lotes e suas características geográficas contribuíram para o desenvolvimento da agricultura familiar. Contudo, o êxodo rural tem-se mostrado constante, como mostra os dados fornecidos pela Emater. Em 2005 havia 1.427 propriedades rurais, destas, 1.330 trabalhavam em regime de agricultura familiar (Paraná, 2005). Já em 2014 restaram somente 1.120 famílias trabalhando desta forma (Paraná, 2014).

Quanto ao êxodo rural brasileiro, Abramovay (1998) nos diz que permanece muito significativo. Em contrapartida, está a precariedade com que os núcleos urbanos absorvem seus migrantes rurais. Existiram várias razões para o êxodo em nosso município e região. Num primeiro momento, quando nossas terras começaram a ser mais valorizadas esses agricultores vendiam suas propriedades para vizinhos ou para alguém interessado e migravam para outras região do país, como o CentroOeste, sobretudo no Estado de Mato Grosso ou Norte, como o Estado de Rondônia, para se dedicarem a atividade rural. Esse movimento ocorreu mais nas décadas de setenta e oitenta.
Segundo Cunha (2013) esses agricultores que migravam para a região de Mato Grosso eram atraídos por programas de colonização da mesma. Lá ocorreu uma articulação entre Estado e detentores de representativos volumes de capital, realizando incentivos para que estes pequenos produtores se engajassem em projetos de colonização, isso por volta dos anos de 1980.

No final dos anos oitenta, houve problemas com crédito rural, o que ocasionou incorporação de áreas. Como nos relata Pinazza (1995), os agricultores tiveram problemas durante o Plano Real em que o preço mínimo dos produtos foram congelados, enquanto o valor do empréstimos agrícolas eram corrigidos pela TR (taxa referencial de juros). Segundo o autor "montou-se um quadro extremamente desfavorável para a agricultura". (p. 18).

A partir de então se tem outro fator importante para o êxodo rural que foi o envelhecimento do campo. Quando da colonização na década de sessenta, quem veio para a região tinha em torno de vinte e cinco, trinta anos. Hoje, cinquenta anos depois esses têm oitenta, ocorrendo à necessidade de repasse dessas propriedades para o seus sucessores. Como se trata de pequenas áreas, uma propriedade seria 
dividida em duas, três ou, até mesmo, quatro e às vezes não se torna sustentável.

De Mello et al. (2003) diz que a busca pelo emprego remunerado pelos jovens do meio rural como assalariado é sempre obrigação ou exclusão. A exclusão da herança da terra, subdivisão da propriedade. Ainda há existência de barreiras na inserção dos jovens na mesma, tais como a falta de acesso a terra, seja pela exclusão na herança, pela posse de uma área de tamanho insuficiente para a reprodução, ou pela inviabilidade de uma exploração agrícola familiar.

\section{Importância da agricultura familiar para a região e para o país}

Quando voltamos nossos olhos para a agricultura familiar, esta pode ser entendida como o cultivo de terra realizado por pequenos proprietários rurais, com mão de obra essencialmente do núcleo familiar. Em relação à agricultura familiar, o entrevistado representante da Emater nos diz que:

Ela é de suma importância porque a agricultura familiar pressupõe propriedades menores, maior numero de pessoas, o envolvimento da família nas atividades, onde a renda fica possibilitando que essas pessoas fiquem empregadas, diretamente em todas as idades. Porque normalmente a agricultura familiar entra em atividades com maior uso de mão de obra e por si só envolve a produção de alimentos que é a atividade leiteira, a atividade hortifruti, a suinocultura, a avicultura.

Segundo Guilhoto (2007) o segmento familiar da agropecuária brasileira $\mathrm{e}$ as cadeias produtivas a ela interligadas respondem por $10,1 \%$ do PIB brasileiro, tendo em vista que o conjunto do agronegócio nacional é responsável por $30,6 \%$ do PIB. Desta forma, um terço do agronegócio brasileiro está condicionado à produção agropecuária familiar. Fica evidente o peso da agricultura familiar na geração de riqueza onde o desempenho recente da agropecuária familiar e do agronegócio a ela articulada vem sendo bastante positivo, superando inclusive, as taxas de crescimento relativas ao segmento da Agricultura patronaliii

Ao abordarmos a agricultura familiar da nossa região, podemos interpretar sua importância na fala do representante da Emater: A agricultura familiar é quem
mantem firme o tecido social da
região sudoeste paranaense e da
região oeste catarinense, mantendo
assim uma segurança em torno da
economia da região, através do
acesso a serviço, ao acesso ao
comércio a permitividade que a
indústria se instale, tendo produtos da
agricultura familiar com uma oferta
regular segura. Trata-se de uma
atividade importante ... que teria que
se olhar muito pra ela pra que ela
fosse mais duradoura no sentido do
tempo e melhor estruturada. Então o
poder público tem que se convencer
que pra manter isso forte, nós temos
que ter no campo acesso a educação, 
acesso a internet, acesso a saúde e renda de forma que as pessoas fiquem desinteressadas em ir disputar espaço nos centros maiores.

O representante da Emater acredita na relação entre agricultura familiar $\mathrm{e}$ segurança alimentar, porque segundo ele:

A agricultura empresarial, quando eu falei de automação e elas se baseiam em pacotes tecnológicos já com aplicações de agrotóxicos de forma preventiva. Porque o grande agricultor empresarial, ele não pode se dar o luxo de esperar o momento de fazer. Isso faz com que na agricultura empresarial o uso de agrotóxico é muito maior, o uso de fertilizantes químicos é maior, porque normalmente eles fazem três safras. Hoje em dia uma terceira safra, safrinha. $\mathrm{O}$ solo muitas vezes ele é mais demandado em termos de nutrientes. Então tem que repor e então a agricultura familiar ela tem muito mais condições de usar menos agroquímicos.

Quando o pequeno produtor acredita que tem a possibilidade de realizar vistorias periódicas valendo-se de técnicas como batida de pano pra detectar a quantidade de pragas e o desfolhamento da soja, cita como exemplo:

Se por um lado, a agropecuária familiar tem um papel social inquestionável, por outro, sua sobrevivência é incerta. Por si só, este setor produtivo é desorganizado e ineficaz para promover seus próprios interesses. O grande número de unidades de produção rural diverge em termos de tamanho, capital e tecnologia, tornando as prioridades individuais diferentes. No caso das propriedades de menor porte, o problema é acentuado, dada à diversidade de sistemas e estratégias produtivas que determinam objetivos difusos, por consequência, a força do setor é diluída em grupamentos locais. Associações e cooperativas possibilitam a permanência do sistema familiar em algumas regiões, mas são totalmente inexistentes em outras. Cabe, então, ao governo e às comunidades a promoção de medidas capazes de alterar os rumos da produção familiar, devido a sua importância estratégica no que se diz respeito ao bem estar geral da sociedade. (Guilhoto, 2007, p. 06).

Diante da forte presença da agricultura familiar na região e de sua importância econômica, bem como social, cultural e ambiental é essencial a presença de políticas públicas que compreendam a importância de sua existência e promova ações para contribuir para a manutenção das famílias no campo. Ao agir desta forma, os governos estariam não apenas assegurando a continuidade deste setor para economia nacional, bem como evitando o deslocamento de populações para centros urbanos como graves problemas em termos de saúde, educação, moradia, transporte público, aumento dos índices de violência e outros. A escola do campo com uma nova proposta, voltada para a realidade das famílias e suas necessidades é uma das ações mais significativas para manter as pessoas no 
seu local de origem e com qualidade de vida.

\section{Implantação das CFRs: Pedagogia da Alternância}

Entendendo a importância da agricultura para a humanidade, especialmente a agricultura familiar como uma questão de segurança alimentar, se faz necessário procurar algo que se contraponha essa atual conjuntura vivenciada pela agricultura familiar. $\mathrm{O}$ êxodo rural persiste devido a fatores como envelhecimento no campo, sucessão familiar, falta de acesso a terra, desorganização por parte do setor e outros, assim tornado sua sobrevivência incerta. Como forma de superar essa conjuntura social surgiram algumas alternativas, como a Casa Familiar Rural (CFR). Estas tiveram sua origem na França em 1937, por iniciativa de um grupo de famílias do meio rural, ao proporem a adoção de uma formação profissional aliada à educação humana para seus filhos, baseada na proposta da Pedagogia da Alternância ${ }^{\text {iv }}$ (PA). Hoje, esta instituição expandiu-se para os cinco continentes, em trinta países, com a mesma concepção, responsabilidade e fortalecimento das famílias na formação dos jovens, no sentido de provocar o desenvolvimento global do meio em que vivem. No Sul do Brasil, o processo de implantação das Casas Familiares Rurais teve início no Paraná, em 1987, nos municípios de Barracão e Santo Antônio do Sudoeste, com discussão dos agricultores e envolvimento das comunidades. Já em 1991, as CFRs foram implantadas nos Estados de Santa Catarina e Rio Grande do Sul e desenvolveram-se também em outros Estados do Brasil (Paraná, 2015).

$$
\text { Palaro (2012) nos diz que a }
$$
implantação das CFRs no Estado do Paraná não aconteceu por acaso. Após as tentativas para a implantação, com pouco apoio local no Nordeste do país, o professor Pierre Gilly ${ }^{\mathrm{v}}$ entrou em contato com Euclides Scalco ${ }^{\mathrm{vi}}$, na época Chefe da Casa Civil do Estado do Paraná. De acordo com o autor, os primeiros contatos foram feitos por volta do ano de 1985. Após isso, houve a realização de palestras sobre as Casas Familiares Rurais, em especial no sudoeste paranaense.

A partir do Decreto $\mathrm{n}^{\circ} 3.106$ de 14 de março de 1994, assinado pelo então governador Roberto Requião, o governo paranaense passou a apoiar a implantação das Casas Familiares. Conforme dispôs o decreto, ficou aprovado o Programa da Casa Familiar Rural, sendo que as Secretarias de Estado do Desenvolvimento Urbano, da Educação, da Agricultura e Abastecimento, da Fazenda e do 
Planejamento e Coordenação Geral e a FAMEPAR (Fundação de Assistência aos Municípios do Estado do Paraná), FUNDEPAR (Fundação Educacional do Paraná) e EMATER, são autorizados a praticar os atos necessários à implantação do projeto referido. Também estabeleceu subsídios referentes à assistência técnica, equipamentos e manutenção das instalações, recursos humanos, e demais ações que visam qualificar o trabalho pedagógico realizado pelas CFRs (Paraná, 1994).

\section{Conforme Batistela (2011 apud} Palaro, 2012), no início da implantação das CFRs a manutenção das Escolas se deu quase que exclusivamente por recursos emanados por Organizações Não Governamentais (ONGs) internacionais. Contudo, com o aumento do número de CFRs, se fez necessário procurar convênios com os municípios e estados, porém, esses recursos oriundos das parcerias feitas via subsídio social, são limitados e muitas vezes descontínuos. Ainda o autor destaca que não existe somente a parceria com o Estado e ressalta a importância de diversas entidades que contribuem para o fortalecimento da Pedagogia da Alternância nas CFRs. Por exemplo, "no Paraná, uma das primeiras a contribuir foi a Union Nationaledes Maisons Familiales Rurales d'Éducationet
d'Orientation (UNMFREO), cujos primeiros contatos com as CFRs ocorreram em meados da década de 1980". (p. 30).

$\mathrm{Na}$ atual conjuntura vivenciada pela agricultura é imposto aos agricultores pacotes e produtos tecnológicos prontos. Isso acaba por interferir nas cadeias produtivas, fazendo com que ocorra a perda de costumes e saberes locais passados de geração para geração. Segundo Bressiani (2012):

Consequentemente percebe-se a
necessidade de uma educação voltada
para o meio rural, que interligue
educação e trabalho no sentido de
desenvolver potencialidades,
considerando as características
próprias das unidades de produção
familiar ... Evidencia-se nas últimas
décadas, demonstradas pelo crescente
êxodo rural, influenciado pelo
modelo capitalista moderno, que
proporcionou um aumento do setor
produtivo e uma contradição: a
exclusão social e aceleração do
número de marginalizados. (p. 42).

Palaro (2012) se vale de diversos autores para nos dizer que a Pedagogia da Alternância trabalha em sincronia com a escola e o trabalho, fazendo com que o jovem continue estudando e, ao mesmo tempo, não se desvincule da família, auxiliando com sua mão de obra. Além disso, essa forma de educação proporciona outras oportunidades, como a promoção do desenvolvimento tecnológico, econômico e 
sociocultural da família do jovem e da comunidade.

A Pedagogia da Alternância trabalha com quatro pilares contendo meios e finalidades. Os meios se constituem como a "alternância", um método pedagógico, a "associação" formada por pais, famílias, profissionais e instituições; as finalidades, "formação integral" através de um projeto profissional e "desenvolvimento do meio" socioeconômico, humano, político. Sua metodologia é composta por instrumentos que possibilitem uma troca de conhecimentos entre família/propriedade e espaço educativo, partindo de um plano de formação construído pelas famílias, monitores e conselho de administração. (Bressiani, 2012, p. 44).

Este plano de formação apresenta temas geradores. Estes conduzem os estudos dos jovens durante o período letivo. Contudo, para trabalhar com este sistema, é preciso se valer de algumas ferramentas como: caderno de alternância; contato individual; plano de estudo; colocação em comum; visita de estudo; visita à propriedade; curso; instrumentos que desempenham uma função necessária para o desenvolvimento do processo educativo (Bressiani, 2012).

O primeiro, a Pedagogia da Alternância, consuma-se, para as Casas Familiares rurais, na alternância de períodos de trabalho na comunidade e estabelecimentos agropecuários, com períodos de estudos na escola formal. O segundo, ao propor uma educação que quer ultrapassar a simples escola para a profissionalização, mas que forme o indivíduo também para as questões gerais presentes no mundo, a formação do "ser humano integral". Nestas condições, unindo os dois elementos, deve-se pensar num conhecimento personalizado. (Oliveira, 2008, p. 286).

É importante ressaltar que a PA se vale das experiências vivenciadas pelo sujeito no seu cotidiano, no convívio familiar, social e profissional, tendo essas como fonte de conhecimentos, como ponto de partida do processo de aprendizagem e como caminho educativo. A Alternância, em comparação com a escola tradicional, inverte a ordem dos processos, colocando em primeiro lugar o sujeito que aprende suas experiências e seus conhecimentos e, em segundo lugar, o programa. Desta forma, o formando não mais recebe um saber exterior, mas, um ator sócio profissional que busca e que constrói seu próprio saber. Ele é sujeito de sua formação e produtor de seu próprio saber (Palaro, 2012).

\section{A Casa Rural Familiar de Realeza/PR}

Nosso campo de pesquisa, a CFR de Realeza PR, situada na linha Sertaneja neste município, implantada em 06 de abril de 2009, foi declarada como Entidade de Utilidade Pública pela Lei municipal 1.256/09 de 18/08/2009. A instituição 
conta com jovens dos municípios de Realeza, Santa Izabel do Oeste e Ampére, formando jovens das mais variadas comunidades rurais destes municípios. Estes cursam o Ensino Médio respectivamente ao curso de Qualificação em Agricultura com ênfase em Agroecologia. A mesma tem grande importância nesta região por ser essencialmente agrícola baseada em sua maioria na agricultura de regime familiar.

A Casa Familiar Rural de Realeza formou sua primeira turma com 12 alunos em 2003 e desse período até a atualidade já formou 43 jovens. Ao todo são duas turmas, divididas da seguinte maneira: o primeiro ano com 20 alunos (16 meninos e 4 meninas), e terceiro ano com 7 alunos (6 meninos e 1 menina). Quanto à turma de segundo ano, em entrevista a coordenadora da CFR nos relata que:

... após o ano 2014 começou um desentendimento entre o Estado e a Arcarfarsul $^{\text {vii }}$. É questão interna de administração da Arcafar com o Estado, situação de prestação de contas etc. Tinha alguns quantos funcionários que ganhavam a mais de que outros, a forma de apresentação de documentos. Não estava de acordo com o Tribunal de Contas. Então isso começou a gerar todo esse problema de atraso salarial, de demissão de funcionário. Esse fecha ... não fecha. Eu cansei de assinar aviso prévio. Já em dois anos eu nem sei quantas eu já assinei e até então o convênio terminaria agora dia 20/12/2015. Todos os funcionários teriam a rescisão de contrato e a partir de 2016 as Prefeituras iriam assumir.

Nos anos de 2014 e 2015 o número de profissionais que aturam na casa se manteve, a não ser pela saída do Engenheiro Agrônomo. Quanto à carga horária, teve uma redução da jornada de trabalho dos professores passando de quarenta horas semanais para vinte horas. Já o tempo de atuação dos profissionais docentes na CFR também se manteve constante. Em 2016 o número de profissionais aumentou, enquanto que o tempo de permanência na instituição diminuiu bastante, uma vez que todos os professores passaram a cumprir apenas as horas/aulas. Podemos perceber com mais clareza esse movimento no Gráfico I. 


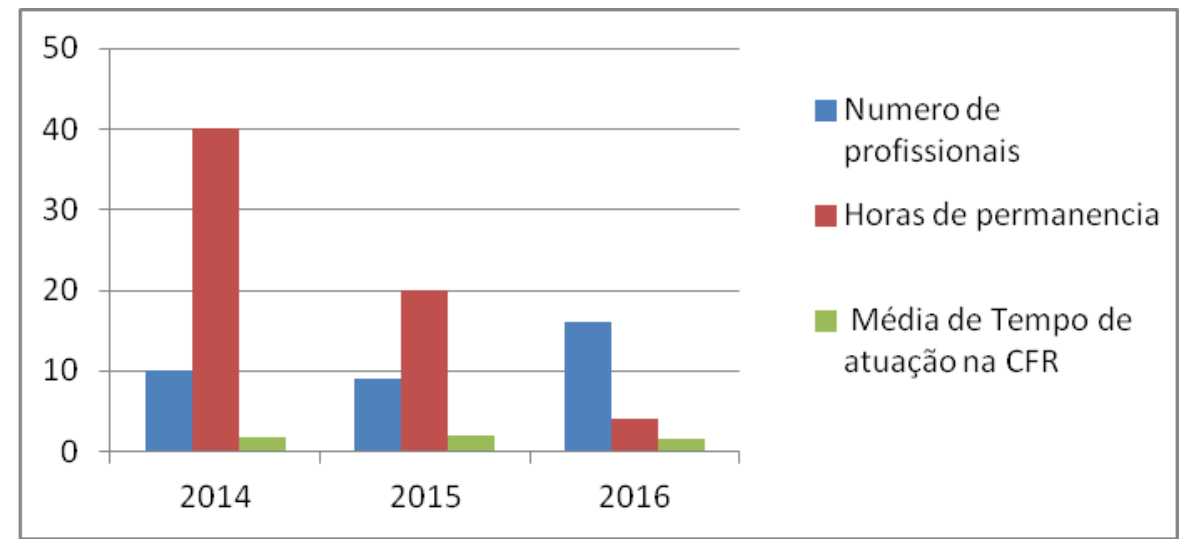

Gráfico I: Número de professores da CFR, horas de permanecia na CFR, média de tempo de atuação na CFR no período de 2014 a 2016.

Fonte: Elaborado pelo autor a partir dos dados fornecidos pela CFR.

Observamos no Gráfico I que o número de profissionais que atuam na CFR aumentou bastante no período de 2014 a 2016, mas, a carga horária diminuiu drasticamente, o que é desfavorável a PA. Já o tempo de atuação na Escola permaneceu constante, o que demonstra que a rotatividade desses profissionais é bastante alta.

Contudo, podemos perceber que o tempo de atuação na CFR por parte dos monitores é muito diverso. Um está quase cinco anos, enquanto o outro há apenas um ano. Entre os professores que atuam na escola, um deles permanece há cinco anos; outro há três anos e outro há 2 anos. O restante, em número de oito, ingressaram este ano na CFR. Dentre todos, o profissional de maior tempo é a Coordenadora da CFR e a professora de biologia a cinco anos. Os demais, o tempo médio de atuação gira em torno de um ano e alguns meses. Isso demonstra haver uma alta rotatividade de profissionais nesta CFR. Sobre isso, é importante destacar que foi visível a alteração do quadro de funcionários mencionado acima, de um ano letivo para o outro, pois, do início da pesquisa (2015) até o presente momento (2016), houve uma rotatividade que se aproxima de $90 \%$.

Em nossa pesquisa podemos notar que a rotatividade dos profissionais que atuam na CFR é muito alta e isso acaba prejudicando os trabalhos, em especial a Pedagogia adotada pela Escola, como fica claro na fala do Prof. 1. "É muito grande a rotatividade, e os próprios técnicos tem bastante rotatividade. Em quatro anos restou eu e a coordenadora da CFR, todos os outros mudaram, desde a cozinheira, o monitor noturno, todo mundo mudou". Além desta rotatividade, ainda há falta de formação específica sobre a Pedagogia da Alternância, o que compromete e muito 
esta proposta de educação. Segundo o prof.1.

Falta bastante na parte pedagógica, falta bastante. Tipo colocaram o filho no mundo e deram para os outros criar, foi meio assim a CFR. Quem entrou aqui para trabalhar tem que se virar, fazer a coisa acontecer. Quando eu entrei aqui, no primeiro ano a gente não tinha a mínima noção de como funcionava a pedagogia da alternância e nós entramos em fevereiro e fomos ter um treinamento de dois dias em maio. Dos que entraram naquela época eu sei falar pra eles como é que tem que fazer, más não é nunca um curso. Eu acho que tinha que ser anual.

O que observamos na CRF de Realeza é um pouco dos contrastes da educação pública brasileira, realidade esta que foi levada para a educação no campo e para as CFRs do Paraná, onde o quadro docente está sempre mudando. Essa rotatividade está longe de ser positiva para qualquer escola, sendo ela rural ou urbana. Quando falamos das CFRs percebemos que está muito distante dos princípios básicos da PA. Refletindo sobre o problema, nos indagamos a respeito de algumas questões: Como oferecer aos jovens uma educação adequada a sua realidade, que lhes permitam condições de exercerem plenamente a cidadania sem ao menos conhecer essa realidade? Alguém que fica apenas algumas horas na CFR, por alguns meses, como pode criar vínculos com a mesma, com os alunos e suas famílias e com PA? Acreditamos que esse sistema de hora/aula, imposto pelo Estado compromete a real proposta da PA. A falta de interação dos profissionais com o trabalho pedagógico, bem como com comunidade prejudica a construção do saber coletivo.

A CFR está instalada em uma antiga edificação de escola rural municipal desativada. Esta estrutura foi cedida pelo município e que não fora projetada para comportar uma CFR. Contudo, o espaço físico da escola conta com duas salas de aula, três dormitórios com banheiros, sendo dois dormitórios masculinos e um feminino, dois banheiros sociais, um pátio coberto com piso de chão batido, uma cozinha com equipamentos semiindustriais, local onde são preparadas as refeições dos alunos e também onde se tem aulas prática de agroindústria de alimentícios e um almoxarifado. Já a biblioteca, a secretaria e sala dos professores dividem o mesmo espaço. A edificação ainda dispõe de refeitório para os alunos que também é usado como sala de TV. Possui uma horta escolar local, onde os alunos tem aula teórico/prática de olericultura orgânica, sendo que a produção é utilizada na alimentação dos alunos. Conta ainda com uma quadra de esportes descoberta e em péssimas condições de uso. Como recursos 
tecnológicos, a Escola dispõe de dois televisores, um vídeo DVD, dois televisores com pendrive, uma máquina fotográfica digital e dois computadores que são de uso coletivo. Há também um veiculo disponibilizado pelo município para uso da CFR.

A manutenção da CFR ocorre da seguinte forma, como nos informa a coordenadora:

Tem uma associação que se chama ARCAFAR/SUL. Ela é uma entidade privada. Ela cuida das Casas Familiares, mas através de convenio com o estado. Então o estado fornece os professores. Nesse convênio com a ARCAFAR ele paga uma cozinheira, um auxiliar noturno um, dois e até três monitores que sejam eles técnicos agropecuários ou zootecnistas veterinário ou engenheiro agrônomo. Depende do tamanho da Casa Familiar, do numero de alunos. Uma associação lá da França que é onde originou as CFRs que esse sistema vem de lá. Essa até onde eu sei, ela repassa para a ARCAFAR ... e, além disso, também tem a parceria com a prefeitura pra manter a parte de alimentação, do transporte de um carro pra visitar e manutenção do prédio que acredito que a maioria das casas os prédios são municipais. Fora isso a gente busca parceria com empresas pra ajudar manter. Porque queira ou não, tem gastos e o estado fornece a merenda escolar, mas nem sempre é suficiente é os funcionários da ARCAFAR quem mantém é o Estado.

As CFRs no Paraná estão vinculadas a uma escola estadual, denominada Escola Base $^{\text {viii }}$ a qual disponibiliza os profissionais para as áreas do Ensino Fundamental ou Médio, conforme a necessidade de cada CFR. São as escolasbase que gerenciam a vida Escolar dos jovens que frequentam as CFRs e que, ao final dos cursos, fazem a certificação. Dessa forma, para todos os efeitos legais, os alunos dessas instituições são parte da rede pública estadual. Assim, no Paraná todas as CFR são dependentes de uma escola-base, para assuntos referentes à documentação escolar e também à lotação e encontros para capacitação dos professores que são cedidos.

Os professores oriundos do Estado deveriam participar de todas as ações na CFR e, por isso, também deveriam acompanhar os monitores nas visitas que eles realizam periodicamente às propriedades das famílias dos jovens. Entretanto, a partir do ano de 2014, isso não foi mais possível, devido à redução da carga horária destes profissionais. Já para o ano de 2016, os professores passaram somente a ministrar as aulas no sistema de hora-aula como se fosse uma escola urbana.

Palaro (2012) traz uma entrevista com a coordenadora pedagógica da Arcafar/Sul. A mesma comenta que:

A relação entre o Estado e as CFR é perigosíssima, pois se pode perder facilmente o ponto de partida, ou seja, a essência das casas. Isto é, são 
as associações que tomam as decisões e não o Estado. Se isso se perder, perde-se a característica da CFR e da Pedagogia da Alternância". Para ela, o trabalho é educativo e se estabelece uma relação formativa entre o trabalho (na propriedade) e a educação (na CFR). Segundo a coordenadora, "espera-se que o jovem permaneça no campo, mas se ele quiser sair, que seja por opção, e não por falta de oportunidade de ficar na roça $\ldots$ O governador em exercício, o professor Flavio Arns, assinou por 4 anos uma parceria com as CFRs, pois todos os anos as CFR tinham que correr atrás do Estado para renovar esse contrato, pois as CFRs dependem desse contrato, pois o Estado cede os professores e a verba por aluno ... ainda no que se refere à relação da PA com o Estado; o Estado está interessado nessa modalidade de educação para o campo e o Estado, nesse momento está vendo com bons olhos a PA, isso no $\mathrm{PR}$, pois em $\mathrm{SC}$ e $\mathrm{RS}$ não funciona assim, nesses Estados a coisa anda devagar, (não esta consolidado ainda a PA), por isso o baixo número de CFRs. No Paraná, a PA já está consolidada. (p. 37).

\section{A CFR Realeza tem como Escola} Base o Colégio Estadual de Flor da Serra Ensino Fundamental e Médio pertencente ao município de Realeza. A localidade de Flor da Serra encontra-se na PR-182, KM 75. Consta no Projeto Político-Pedagógico da instituição que ele foi elaborado por meio da participação coletiva dos segmentos que compõem a comunidade escolar, baseado na legislação vigente. A gestão democrática e colegiada da instituição escolar é entendida como o processo que rege o funcionamento da mesma, compreendendo a tomada de decisões conjuntas na execução, acompanhamento e avaliação das questões administrativas e pedagógicas, envolvendo a participação de toda comunidade escolar por meio da representação do Conselho Escolar. Traz em seu objetivo a socialização do conhecimento científico, a produção de novos conhecimentos, proporcionando condições para que os educandos se tornem cidadãos críticos (Paraná, 2011).

A CFR nasceu dos movimentos sociais e das organizações sociais do campo, surgiu de lutas de quem estava inconformado com a situação vigente. Ela surgiu do meio dos sem-terra, dos pequenos agricultores, dos atingidos por barragens, das mulheres camponesas, da juventude do campo, do meio das pastorais. E surgiu com a ajuda de vários estudiosos da educação brasileira. A Educação do Campo deve ter como finalidade a produção e o trabalho como princípios educativos (Paraná, 2012). Assim, perguntamos aos professores da CFR como que eles entendem o papel da mesma no contexto que está inserida. Eles comentam que:

Eu penso que a casa familiar é essencial porque a ideia da CFR é essa. É a agricultura familiar. É manter os filhos dos agricultores com instrução, com informação, com 
objetivo de ficar no campo. A função da CFR é que os filhos dos agricultores não tenham a ideia de se desfazerem da terra que os pais vão ficando velhos e vão perdendo a capacidade de trabalhar no campo, pra que eles continuem ... Então, as CFR são pontuais pra isso, se o objetivo é manter o filho do agricultor no campo não pode se fechar, se extinguir ... Enquanto agricultura familiar eu acho que nada melhor que a CFR para incentivar que eles fiquem (Professor 1).

Eu acho que a casa tá dando uma formação diferenciada ... Eles tem iniciativas aqui que eles tão se formando líderes. Muitos se formam líderes do grupo isso vai refletir lá na sociedade, lá na comunidade dele que ele vai se tornar um líder da igreja, do grupo da agricultura, da cooperativa. De repente um líder político porque aqui exige isso que eles saiam do anonimato. Ele tem que fazer projeto, ele tem que expor, ele tem que falar, ele tem que sair daquele mundinho que ele tá vivendo porque geralmente eles veem dentro de um casulo e chega aqui, ele tem que se abrir. Ele tem que se expor, seja da forma que eles trás a bagagem dele, mas ele tem que se expor e isso vai refletir lá na vida dele (Professor 2)

Quanto à concepção que os pais têm a respeito do papel da CFR frente à agricultura familiar, estes também entendem a mesma como um instrumento de formação diferenciada, voltada para o jovem do campo visando à sucessão familiar e promovendo a permanência desse estudante no campo. Como podemos observar na fala do Pai1. "Ah! O papel dela seria incentivar permanecer na agricultura, e o ensinamento pra ter conhecimento da agricultura pro futuro".

Podemos notar na fala dos professores e pais que há uma preocupação em qualificar os jovens para o trabalho agrícola para ser posto em prática na propriedade durante e após a conclusão do curso. Percebemos que há uma preocupação com a formação profissional, o que é muito importante. Entretanto, nada se fala a respeito de preparar os jovens para uma formação critica e emancipatória.

O que podemos perceber é que os profissionais e familiares não percebem que a PA transcende os limites da formação para o trabalho e sim para um nível elaborado de conscientização e humanização.

\section{Casa Familiar Rural Realeza: práticas pedagógicas}

Para retratar a vivência da CFR em relação a PA percebemos a presença de vários instrumentos pedagógicos que a caracterizam. Estes instrumentos orientam o processo de formação dos jovens que a vivenciam. Estas ferramentas pedagógicas utilizadas unicamente pela PA têm sua dinâmica delineada no início do período letivo de cada ano.

Vários são os elementos que compõem a Pedagogia da Alternância e que fazem dela um modelo pedagógico voltado para o 
atendimento dos jovens que vivem no campo. Esses elementos são, pois, instrumentos que organizam o trabalho pedagógico e direcionam o processo de formação dos jovens dos Ceffas $^{\text {ix }}$, permitindo a reflexão nos diferentes espaços: escolar, familiar, comunitário e profissional. (Matos, 2014, p. 48).

Segundo Matos (2014) o processo inicia-se por uma Pesquisa Participativa realizada pela Associação das CFRs, envolvendo monitores, professores e lideranças da comunidade, no intuito de elaborar um diagnóstico dos aspectos que envolvem toda comunidade, as atividades produtivas ou não. Juntamente com as famílias, refletem sobre problemas e soluções possíveis. Esta atividade dá origem ao Plano de Formação, o qual prioriza a experiência como lugar de aprendizagem e formação.

A partir do Plano de Formação se tem os Temas Geradores que são temas próximos das vivências familiares dos jovens. Este é um dos instrumentos pedagógicos da PA. Já no início da semana, um tempo é reservado para os monitores programarem com os jovens como será desenvolvido o trabalho na semana da alternância, baseando-se nos Temas Geradores, como por exemplo, a fruticultura, orilicultura, suinocultura. Os jovens apresentam seus questionamentos sobre o tema que será trabalhado naquela semana e que deverão ser respondidos.
Os Temas Geradores que norteiam os trabalhos na CFR devem ser articulados com os conteúdos da Base Nacional Curricular Comum. Estes temas são fruto da participação e construção de funcionários da CFR, juntamente com as famílias e comunidade. Segundo Bressiani (2012):

É uma experiência interdisciplinar importante no desempenho das atividades que resgatam valores solidários voltados para a soberania alimentar e, em seu contexto estabelece relações de reciprocidade constantes. Isso se evidencia quando o plano de formação desenvolvido como eixo central de formação pode resgatar as questões de sustentabilidade. Todos os professores, monitores e famílias ... devem proporcionar conteúdos que contribuam para um raciocínio ordenado, voltado para o calendário agrícola combinados com as necessidades e anseios de seus atores, envolvidos, elaborando temas geradores que envolvam a formação científica, conhecimentos empíricos e trabalhe com perspectivas sustentáveis. (p. 50).

A partir dos Temas Geradores se tem as aulas teórico/práticas durante a semana articulados com os conteúdos curriculares da BNCC. Como exemplos, podemos citar que, quando se trabalhava conceitos de botânica em Biologia, se trabalhava plantas medicinais como conteúdo do Tema Gerador. Essa metodologia permite que o Jovem adquira com mais propriedade os conteúdos. Primeiramente em sala de aula, 
os monitores discutem os conceitos teóricos sobre a atividade a ser desenvolvida. Em seguida, esses conhecimentos são revistos na prática.

Durante a semana de permanência na CFR, acompanhados pelos monitores e professores, os jovens fazem a Visita de Estudos, realizada em uma propriedade que desenvolve a atividade do tema gerador. Esse instrumento pedagógico adotado pela PA oferece aos jovens a oportunidade de observarem na prática a atividade, estabelecendo relação com seus conhecimentos. Com isso, os novos conhecimentos adquiridos nas aulas vão sendo somados à experiência que vai sendo construída. Trata-se de uma interessante oportunidade de estreitar as relações entre teoria e prática, na medida em que o jovem começa a perceber que uma não existe sem a outra.

Contudo, a participação dos professores nas atividades desenvolvidas pela CFR ficou comprometida a partir do ano de 2015, como podemos constatar na fala do prof.1:

A Casa abriu para quarenta horas, então os dois padrões era aqui. Eu não assumi outra escola. Aí funcionava esse ano (2015 grifos nossos) que passou. A gente faz só vinte horas. A gente faz um terço do que a gente fazia. Eu acho que essas vinte horas compromete a PA. Nós não conseguimos fazer acompanhamento, antes a gente tinha tudo isso mesclado durante o dia inteiro. Então a gente misturava as aulas da base nacional da educação com as técnicas e a gente podia participar, a gente fazia a recepção deles todos juntos. A gente fazia o enceramento da semana todos juntos e isso não acontece mais porque com vinte horas só dos professores não funciona ... Não podemos fugir da base que eles precisam e não podemos deixar de trabalhar a parte técnica, mas com vinte horas isso tá funcionado bem menos, bem menos efetivo.

$\mathrm{Na}$ semana em que os jovens estão na propriedade rural, além de contribuir com sua mão de obra nas atividades agropecuárias como cultivo de grãos, produção leiteira, suínos, dentre outras, eles têm a oportunidade de por em prática o aprendizado adquirido na CFR com a participação da família. Este é um momento muito importante, como podemos perceber na fala da coordenadora:

Essa semana que eles tão com a família na propriedade eles podem estar aplicando o que eles aprenderam na CFR durante a semana. Então quando você vai pra uma sala da aula e vê como trabalha com canteiro, como plantar um pé de alface, ou como você melhorar a ordenha das vacas. Você chegar em casa e aplicar tem grande significado, por exemplo o leite. E se chegar pra esses produtores mais antigos assim, que eles devem, usar bota, roupa limpa para fazer a ordenha, lavar as tetos das vacas. Eles vão chamar você de louca, ... agora se você trabalha com o jovem e mostra essa realidade, a importância da limpeza da ordenha, a limpeza da sala, a limpeza dos equipamentos e eles chega e faz em casa. Ele vai notar, lá no final do mês, quando ele receber o 
cheque do leite, o popular cheque do leite ... a diminuição das bactérias, e a diminuição de mastite, e a melhoria das pastagens, o melhoramento fitossanitário dos animais ou da horta ou a diminuição da perda por má plantio, enfim por falta de adubação.

Durante esta semana em que os alunos retornam para suas propriedades, as famílias podem receber visitas dos monitores e professores para acompanhamento das atividades desenvolvidas pelo jovem na propriedade e proporcionar orientação técnica. Esse também é um momento de compartilhar conhecimentos empírico e técnico. Esse momento fica claro na fala da coordenadora:

Tem algumas coisas que a gente fala que são dos antigos que hoje a gente vê que dá certo, claro de uma maneira um pouquinho melhorada, mas que dá certo. Por exemplo, você tem que plantar tal cultura em tal lua. Quando você vai pesquisar tem grande influencia sim. Conforme vai plantar uma batata, uma salsinha, em fim ela vai carunchar, ela vai sementar. Esse conhecimento que eles trazem ou alguma maneira que eles estão trabalhando com a terra, ou até mesmo com algum produto natural. Isso contribui bastante porque a experiência deles vai passar para o resto dos colegas, algumas vezes a gente trabalha aqui na horta mesmo e a gente vê que dá certo. Então o empírico e o cientifico eles se complementam, não dá pra trabalhar sozinho.

Para maior aprofundamento dos temas tratados no decorrer do ano letivo a
PA se vale de outro instrumento denominado Intervenção Externa. Esse instrumento é constituído por palestras ou transmissão de algum conhecimento prático, ministrados por agricultores ou técnicos convidados das mais diversas áreas de interesse dos estudantes. Esses convidados geralmente pertencem a entidades públicas e privadas como Emater, Assesoar ${ }^{\mathrm{x}}$, Senar ${ }^{\mathrm{xi}}$, Sindicatos relacionados à agricultura ou próprios agricultores que vivenciam aquela área de interesse. Os convidados colaboram voluntariamente com este processo educativo.

Todas as experiências vividas pelos jovens durante sua formação são registradas no Caderno de Realidade. Esse instrumento tem relevância significativa para a PA. Para Mattos (2014), a sistematização racional da reflexão e ação provocada pelo Plano de Estudos dá origem ao Caderno da Realidade, que consiste no registro e anotações das reflexões e estudos das experiências educativas acontecidas na CFR. Por meio dele os pais ficam por dentro dos acontecimentos que estão ocorrendo na escola, podendo assim contribuir com sugestões e conselhos. Este material acompanha o aluno dentro e fora da CFR.

Outro Instrumento inserido no contexto da PA é o Projeto de Vida. Já no 
primeiro ano de formação os jovens são instigados a construir gradativamente o seu projeto de vida. Esta é a ferramenta pela qual se faz mensuração do seu processo formação.

Desde o início dos estudos na CFR, o jovem já recebe orientações para construir seu Projeto de Vida. Tratase de uma maneira de o jovem concretizar as pesquisas do Plano do Estudo, incitando-o a conhecer melhor a realidade socioeconômica, cultural política profissional e regional. É o momento de pensar no futuro como profissional elaborando um projeto que dê um rumo à sua vida sendo aplicado na sua comunidade ou fora dela Teixeira et al. (2010, p. 60 apud Matos 2014, p. $65)$.

Pelo que observamos em nossa pesquisa sobre o Projeto de Vida do Jovem construído na CFR de Realeza, podemos dizer que este vem contribuindo significativamente para a manutenção do homem no campo, para a melhoria da qualidade de vida dos envolvidos, contribuindo efetivamente para a melhoria da qualidade de vida dos trabalhadores do campo. No período de desenvolvimento deste trabalho, visitamos quatro propriedades de pais de alunos e ex-alunos, onde seus filhos implantaram seus projetos. Na propriedade do Pail foi implantado o projeto de fumicultura, atividade já desenvolvida na família por três gerações.
$\mathrm{Na}$ propriedade do Pai2 foi implantado o projeto de cultivo hidropônico, onde parte da produção é vendida para merenda escolar. O Pai3 cedeu parte da área da sua propriedade para o filho dar início a criação de gado para a produção leiteira. Já na propriedade do Pai4 que teve sua filha formada em 2012 o projeto inicial foi à implantação de uma agroindústria de panificação e confeitos. Atualmente, a propriedade desenvolve mais atividades, além da agroindústria como o cultivo de hortifrutis, citros, tomate e banana. A produção é vendida para a merenda escolar e feira livre.

Além da implantação e viabilização dos projetos de vida, outra observação que chama atenção foi referente à preocupação com o meio ambiente. A Pedagogia da Alternância é voltada para uma educação com um foco na sustentabilidade e a preservação ao meio ambiente, como nos relata à coordenadora:

Principalmente, na turma de primeiro ano a gente trabalha muito essa questão de organizar a propriedade, a questão de meio ambiente, a questão dos agrotóxicos e de mata. Então, é que nem eu falei. Produzir com qualidade sem agredir o meio ambiente, porque pequena propriedade se a gente, claro que tem anos difíceis, de muitas pragas, de muitas doenças. Mas se a gente ter o foco e tem vontade pra trabalhar com produção 
orgânica ou pelo menos diminuir o uso de agrotóxicos, a gente consegue e trabalhar a terra ou um pedaço de terra que seja. Seja ele pequeno, sem tá precisando derrubar mata, sem né tá derrubando, preservando as nascentes, os rios ... Então, esse trabalho a gente faz, pelo menos a gente tenta convencer os jovens a família pra esse lado do ambiental.

Este interesse é levado com os jovens até as propriedades rurais, como podemos perceber na fala do Pai2;

Desde começo ele falava alguma coisa que lá tem uma sanguinha à fonte de água. Lá aonde ele foi, tem que hoje é obrigado a conservar. Mas ele falou que não podia mexer na verada da sanga do mato e o poço também tem que fazer a proteção certinha. Tudo eu acho que ajuda sim.

Quando a preocupação com o desenvolvimento sustentável e a preservação ambiental, a possibilidade de garantir mudanças sociais e políticas vão de encontro aos anseios da PA. Acreditamos que a educação ambiental é prioritária para viabilizar uma prática conservacionista que articule de forma incisiva a necessidade de se enfrentar a degradação ambiental e os problemas sociais. Para Jacobi (2003) o entendimento sobre os problemas ambientais se dá por uma visão do meio ambiente como um campo de conhecimento e significados socialmente construído, que é perpassado pela diversidade cultural e ideológica e pelos conflitos de interesse. Esse universo de complexidades precisa situar o aluno, cujos repertórios pedagógicos devem ser amplos e interdependentes, visto que a questão ambiental é um problema híbrido, associado a diversas dimensões humanas.

\section{Considerações finais}

É importante destacar inicialmente que este estudo não tem a pretensão de esgotar as discussões sobre o assunto, mas, sim, trazer algumas reflexões a respeito e que de algum modo possam contribuir com a proposta das CFRs.

Fazendo uma análise sobre o lócus da pesquisa e comparando entre o que dizem os teóricos, concluímos que, de acordo com os pensadores da PA, está distante a realidade vivenciada na CFR de Realeza, pois conforme observamos em nossa pesquisa, esta não deu mostras de conhecer os instrumentos pedagógicos da PA com propriedade e, a equipe pedagógica, em sua grande maioria, parece não os conhecer muito bem e nem os jovens os conhecem. Acreditamos que seja devido à dependência do Estado e a alta rotatividade dos que ali exercem sua profissão.

Outra conclusão que chegamos nesta linha de entendimento é que a relação entre 
a CFR e o Estado do Paraná se mostra concentrada na CFR de Realeza, o que acaba provando que essa ideia de resistência não se fundamenta, pois, o Estado subjuga a CFR deixando-a dependente da estrutura burocrática, pedagógica e financeira.

Outro aspecto que aparece na CFR de Realeza é a questão do desenvolvimento teórico em sala de aula sobre o trabalho qualificado para ser posto em prática na propriedade, após a conclusão do curso que qualifica os jovens para o trabalho agrícola. Uma das percepções que tivemos a respeito da formação dos jovens é que a CFR pouco prepara os jovens para uma formação critica e emancipatória. Preparaos para o trabalho sim, porém de uma maneira tecnicista. Acreditamos que a mesma poderá contribuir com uma educação emancipadora desde que se desvencilhe das prerrogativas curriculares do Estado. Contudo não se deve abrir mão do custeio financeiro do Estado, mas ter autonomia pedagógica. Constatamos que um dos principais objetivos é a permanência do jovem no campo como agente de desenvolvimento. Um dos aspectos positivos que a pesquisa aponta é que um percentual significativo dos jovens tem a pretensão de permanecer no campo. Nada impede que os jovens busquem outras opções, talvez não por vontade, mas por obrigação. Alinhado a isso observamos que a CFR tem dado sua contribuição, embora modesta para o desenvolvimento do município e região. O Projeto de Vida do Jovem contribuiu, e vem contribuindo significativamente para a manutenção do homem no campo, para a melhoria da qualidade de vida dos envolvidos, de suas famílias e de suas comunidades.

Até aqui destacamos o que foi possível verificar com a pesquisa. Contudo, nos propomos a dar prosseguimento na investigação no intuito de poder contribuir com as Casas Familiares Rurais e a sua pedagogia.

\section{Referências}

Abramovay, R. (1998). Agricultura familiar e desenvolvimento territorial. Reforma Agrária-Revista da Associação Brasileira de Reforma Agrária, 123(28), 2-18. Disponível em:http://ricardoabramovay.com/categoria/ artigos-cientificos/page/7/ Acesso em: 14 maio 2015.

Bressiani, C. M. W. (2012). Formação por alternância e a sustentabilidade da agricultura familiar. (Dissertação de Mestrado). Universidade Tecnológica Federal do Paraná.

Cunha, J. M. P. (2013). Dinâmica migratória e o processo de ocupação do Centro-Oeste brasileiro: o caso de Mato Grosso. Revista Brasileira de Estudos de População, 87-107.

De Mello, M. A. et al. (2003). Sucessão hereditária e reprodução social da agricultura familiar. Agri, 11-24. 
Gomes, I. Z. (2005). 1957 a revolta dos posseiros. Curitiba PR: Criar Edições Ltda.

Guilhoto, J. et al. (2007). A Importância da Agricultura Familiar no Brasil e em seus estados (Family Agriculture's GDP in Braziland in It'sStates). $V$ Encontro Nacional da Associação Brasileira de Estudos Regionais e Urbanos.

Haygert, A. M. G. (2006). Entrevista Euclides Scalco O cruzado tucano. Instituto Ciencia e Fé. Curitiba PR. Disponível em: 〈http://www.cienciaefe.org.br/jornal/ed77/ mt05.htm>. Acesso em: 07 jun. 2016.

Jacobi, P. (2003). Educação Ambiental, Cidadania E Sustentabilidade. Cadernos de Pesquisa, 1(1), 189-205. Disponível em: <http://www.scielo.br/pdf/ /cp/n118/16834.pdf $>$. Acesso em: 17 maio 2016.

Mattos, L. M. S. (2014). O plano de formação no contexto da pedagogia da alternância: articulações entre temas geradores e conteúdos do ensino médio na Casa Familiar Rural de Cruz Machado $P R$. (Dissertação de Mestrado). Universidade Tecnológica Federal do Paraná.

Martins, R. S. (1986). Entre jagunços e posseiros. Curitiba PR: Estúdio GPS.

Oliveira, M. A. (2008). As bases filosóficas e epistemológicas de alguns Projetos de Educação do Campo: do pretendido Marxismo à aproximação ao Ecletismo Pós- Moderno. (Tese de Doutorado). Universidade Federal do Paraná.

Paraná. (2015). Secretaria de Educação. Programas e Projetos - Casa Familiar Rural. Disponível em: http://www.educacao.pr.gov.br/modules/co nteudo/conteudo.php?conteudo=136.

Acesso em: 14 maio 2015.
Paraná. (2005). Perfil da realidade agrícola municipal. Realeza PR: Emater.

Paraná. (2014). Perfil da realidade agrícola municipal. Realeza PR: Emater.

Palaro, R. (2012). Análise sobre a formação para o trabalho na Pedagogia da Alternância na Casa Familiar Rural de Manfrinópolis - PR: possibilidades $e$ limites. (Dissertação de Mestrado). Universidade Tecnológica Federal.

Paraná. (1994). Decreto $n^{\circ} 3.106$, de 14 de março de 1994. Aprovação do Programa da Casa Familiar Rural nos termos do estudo em anexo no presente Decreto. Casa Civil do Governo Estadual do Paraná. CuritibaPR. Disponível em: http://www.legislacao.pr.gov.br/legislacao/l istarAtosAno.do?action=iniciarProcesso\&t ipoAto $=11$ \&orgaoUnidade $=1100 \&$ retiraLi sta $=$ true \&site $=1$. Acesso em: 15 abr. 2016.

Pinazza, L. A. (1995). Agricultura e Plano Real: causa e efeito. Agroanalysis, 15(8), 18-20.

Paraná. (2011). Plano Político Pedagógico - PPP Colégio Estadual de Flor da Serra Ensino Fundamental e Médio. Realeza PR.

Paraná. (2016). Secretaria da agricultura e abastecimento. Emater Instituto Paranaense de Assistência Técnica e Extensão Rural. Atuação e estratégia. Disponível em: <http://www.emater.pr.gov.br/modules/con teudo/conteudo.php? conteudo $=88>$.

Acesso em: 25 ago. 2016.

\footnotetext{
i Empresa de Assistência Técnica e Extensão Rural: Uma de suas funções é orientar os agricultores familiares e suas organizações no desenvolvimento de sistemas de produção para que os mesmos sejam sustentáveis e gerem renda suficiente para conferir competitividade aos negócios que sustentam as propriedades rurais e permitem às famílias rurais vida diga e com qualidade (Paraná, 2016).
} 
${ }^{\text {ii } U m ~ h e c t a r e, ~ r e p r e s e n t a d o ~ p e l o ~ s i ́ m b o l o ~ h a, ~ e ́ ~ u m a ~}$ unidade de medida de área equivalente a 10.000 (dez mil) metros quadrados.

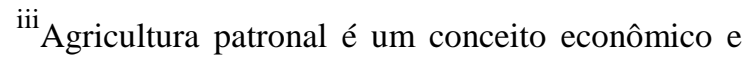
jurídico adotado no Brasil, que se contrapõe à agricultura familiar, e que conta, em sua produção, com empregados permanentes ou temporários.

${ }^{\text {iv }}$ A Pedagogia de alternância intercala um período de convivência na sala de aula com outro no campo para diminuir a evasão escolar em áreas rurais.

${ }^{\mathrm{v}}$ Assessor da UNMFRs (União Nacional das Maisons Familiares Rurales) no Brasil. Veio para o Brasil em 1980 para divulgar e implantar a proposta da pedagogia da alternância.

vi Italo-gaúcho nascido em 1932, em Nova Prata RS, forjado homem público no Sudoeste do Paraná. Foi o farmacêutico em Francisco Beltrão PR, vereador e prefeito. Contribui-o para a criação da Assessoar, líder de amplo movimento pela legitimação das terras que causara o grande levante de colonos, em 1957 (Haygert, 2006).

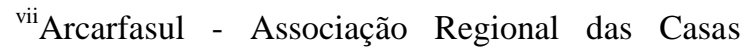
Familiares Rurais do Sul do Brasil

viii Uma escola-base é uma Escola Estadual, no mesmo município de instalação da CFR e que a escola responsável pela documentação escolar dos jovens alternantes e pela certificação tanto do Ensino Médio como do curso técnico realizado na CFR.

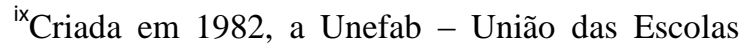
Famílias Agrícolas do Brasil. A Unefab, junto com as Casas Familiares Rurais, congregam os Ceffas Centros de Formação por Alternância, que então passam a organizar as experiências tanto de EFAs como de CFRs (Matos, 2014, p. 25).

${ }^{x}$ Associação de Estudos, Orientação e Assistência Rural, é uma entidade jurídica de direito privado, de caráter educacional e filantrópico, sem fins lucrativos.

${ }^{x i} \mathrm{O}$ Serviço Nacional de Aprendizagem Rural é uma entidade vinculada a Confederação da Agricultura e Pecuária do Brasil que tem como objetivo organizar, administrar e executar, em todo território nacional, a Formação Profissional Rural e a Promoção Social de jovens e adultos que exerçam atividades no meio rural.
Recebido em: 05/10/2016

Aprovado em: 19/10/2016

Publicado em: 13/12/2016

Como citar este artigo / How to cite this article / Como citar este artículo:

APA:

Garcia, R. A. G., \& Barbacovi, E. A. (2016). Contribuição da Casa Rural Familiar para a permanência da família no campo: o caso de Realeza/PR. Rev. Bras. Educ. Camp., 1(2), 428-452.

\section{ABNT:}

GARCIA, R. A. G.; BARBACOVI, E. A. Contribuição da Casa Rural Familiar para a permanência da família no campo: o caso de Realeza/PR. Rev. Bras. Educ. Camp., Tocantinópolis, v. 1, n. 2, p. 428-452, 2016. 